\title{
Spatiotemporal pattern formation in a three-variable CO oxidation reaction model
}

\author{
I.S. Bzovska, I.M. Mryglod \\ Institute for Condensed Matter Physics of the National Academy of Sciences of Ukraine, \\ 1 Svientsitskii St., 79011 Lviv, Ukraine
}

Received February 16, 2018, in final form May 2, 2018

\begin{abstract}
The spatiotemporal pattern formation is studied in the catalytic carbon monoxide oxidation reaction that takes into account the diffusion processes over the $\mathrm{Pt}(110)$ surface, which may contain structurally different areas. These areas are formed during CO-induced transition from a reconstructed phase with $1 \times 2$ geometry of the overlayer to a bulk-like $(1 \times 1)$ phase with square atomic arrangement. Despite the CO oxidation reaction being non-autocatalytic, we have shown that the analytic conditions of the existence of the Turing and the Hopf bifurcations can be satisfied in such systems. Thus, the system may lose its stability in two ways - either through the Hopf bifurcation leading to the formation of temporal patterns in the system or through the Turing bifurcation leading to the formation of regular spatial patterns. At a simultaneous implementation of both scenarios, spatiotemporal patterns for $\mathrm{CO}$ and oxygen coverages are obtained in the system.
\end{abstract}

Key words: reaction-diffusion model, spatiotemporal patterns, the Hopf bifurcation, the Turing bifurcation

PACS: $82.40 . B j, 82.45 . J n$

\section{Introduction}

In recent times, spatiotemporal pattern formation in spatially extended systems, such as reactiondiffusion systems, has been extensively studied [1-4]. In these systems, the concentration of one or more substances distributed in space can change under the influence of two processes: local chemical reactions in which the substances transform into each other, and diffusion which causes the substances to spread out over a surface in space.

Among chemical systems, the catalytic oxidation of CO on platinum (110) is one of the most prominent examples of a reaction-diffusion system showing a variety of complex spatiotemporal patterns [5-8]. For this system, various experiments on pattern formation have been carried out. Pattern formation was monitored by means of photoemission electron microscopy (PEEM) [9-11]. The experimental parameters were chosen such that the reaction was oscillatory and, furthermore, uniform oscillations were unstable and a complex state of spiral-wave turbulence spontaneously developed.

An orientation of the catalyst surface in such systems decisively influences the occurrence of oscillations and surface patterns [3, 5, 6]. A clean Pt(110) top surface layer reconstructs into a $1 \times 2$ "missing row" structure. This reconstruction can be reversibly lifted by adsorption of CO molecules. Since oxygen adsorption is favoured on the unreconstructed $1 \times 1$ phase, a periodic switching can occur between two states of a different catalytic activity resulting in temporal oscillations of the reaction rate. Local spatial coupling across the catalytic surface is provided by surface diffusion of adsorbed $\mathrm{CO}$ and oxygen. Under such oscillatory conditions, the interplay between the reaction and diffusion processes can lead to the development of spatiotemporal patterns.

The formation of spatiotemporal patterns occurs under two main symmetry-breaking instabilities such as the Hopf and the Turing ones [12, 13]. An interaction and competition of these bifurcations have been considered for different reaction-diffusion systems, including Belousov-Zhabotinsky autocatalytic 
reaction [14], the FitzHugh-Nagumo model [12, 13], etc. In these models, a variety of modes has been received, including mixed modes, i.e., spatial patterns modulated in time.

In this paper, we study the mechanisms of spatiotemporal pattern formation in the carbon monoxide oxidation reaction on the surface of $\mathrm{Pt}(110)$. A simple three-variable model has been developed to account for most of the dynamic features of the reaction. The main purpose of the study is to determine whether a combined scenario of the formation of dissipative patterns is possible in this three-variable model and under what conditions. The analysis of instabilities in time and space of the system is based on the methods of linear stability theory and numerical modelling. It is shown that conditions for the existence of the Turing and of the Hopf bifurcations can be satisfied in such non-autocatalytic systems. As a result, this leads to the formation of dissipative patterns.

The paper is organized as follows. A model of the catalytic oxidation reaction of carbon monoxide and the linear stability theory are introduced in the next section. In section 3 , the results of our calculations and a discussion of the obtained results are presented. The paper ends with conclusions in section 4

\section{Model and theory}

Let us consider a model of the catalytic oxidation reaction of carbon monoxide that takes the diffusion processes over the $\operatorname{Pt}(110)$ surface into account. The model was first introduced in 1992 by Krischer, Eiswirth and Ertl [15] without the diffusion terms. Later on, it was extended to include diffusion terms for the $\mathrm{CO}$ species by Bär et al. to account for the pattern formation behaviours observed in experiments [16]. We include the diffusion terms into the system of kinetic differential equations for all species [17, 18]:

$$
\begin{aligned}
& \frac{\mathrm{d} \theta_{\mathrm{CO}}}{\mathrm{d} \tau}=D_{1} \Delta \theta_{\mathrm{CO}}+p_{\mathrm{CO}} k_{\mathrm{CO}} s_{\mathrm{CO}}\left(1-\theta_{\mathrm{CO}}^{q}\right)-d \theta_{\mathrm{CO}}-k_{\mathrm{r}} \theta_{\mathrm{CO}} \theta_{\mathrm{O}}, \\
& \frac{\mathrm{d} \theta_{\mathrm{O}}}{\mathrm{d} \tau}=D_{2} \Delta \theta_{\mathrm{O}}+p_{\mathrm{O}_{2}} k_{\mathrm{O}}\left[s_{1 \times 1} \theta_{1 \times 1}+s_{1 \times 2}\left(1-\theta_{1 \times 1}\right)\right]\left(1-\theta_{\mathrm{CO}}-\theta_{\mathrm{O}}\right)^{2}-k_{\mathrm{r}} \theta_{\mathrm{CO}} \theta_{\mathrm{O}}, \\
& \frac{\mathrm{d} \theta_{1 \times 1}}{\mathrm{~d} \tau}=D_{3} \Delta \theta_{1 \times 1}+k_{5}\left\{\left[1+\exp \left(\frac{u_{0}-\theta_{\mathrm{CO}}}{\delta u}\right)\right]^{-1}-\theta_{1 \times 1}\right\} .
\end{aligned}
$$

Equation (2.1) describes the change of the number of adsorbed $\mathrm{CO}$ that takes into account the chemical reaction with adsorbed oxygen, desorption of $\mathrm{CO}$ with desorption constant $d$ and diffusion of $\mathrm{CO}$. Equation 2.2 describes the diffusion of oxygen, its dissociative adsorption and changes due to CO oxidation reaction. In many models, the diffusion of oxygen is usually neglected compared to that of CO. Here, we take it into account and consider the diffusion coefficient of adsorbed oxygen being about three orders of magnitude lower than the $\mathrm{CO}$ diffusion parameter [8]. Equation $[2.3$ ) is a kinetic equation for the surface transformation. Function $\left\{1+\exp \left[\left(u_{0}-\theta_{\mathrm{CO}}\right) / \delta u\right]\right\}^{-1}$ is a nondecreasing and smooth function of $\theta_{\mathrm{CO}}$ at the interval [0,1], which allows us to describe the transformation of the reconstructed $1 \times 2$ surface structure into the $1 \times 1$ structure depending on the amount of $\mathrm{CO}$ coverage [6]. For an inhomogeneous surface, the Laplacian term $\Delta \theta_{1 \times 1}$ in equation (2.3) originates from the contribution of the interfaces between different surface geometries to the total system energy [8]. Consequently, the coefficient $D_{3}$ describes the energy costs of such interfaces. In this model, the precursor-type kinetics of $\mathrm{CO}$ adsorption is accounted for by the exponent $q=3$ in the right-hand side of equation (2.1). It makes the model more realistic since the inhibition of adsorption of $\mathrm{CO}$ and $\mathrm{O}_{2}$ is asymmetric, and the preadsorbed $\mathrm{CO}$ blocks the oxygen adsorption but not vice versa. A more detailed explanation and values of the parameters used in further calculations are presented in table 1 .

System (2.1)- 2.3 ) can be transformed by substitution

$$
\begin{aligned}
& t=k_{\mathrm{r}} \tau, \quad \bar{D}_{1,2,3}=D_{1,2,3} / k_{\mathrm{r}}, \quad \bar{p}_{\mathrm{CO}}=p_{\mathrm{CO}} k_{\mathrm{CO}} s_{\mathrm{CO}} / k_{\mathrm{r}}, \\
& \bar{p}_{\mathrm{O}_{2}}=p_{\mathrm{O}_{2}} k_{\mathrm{O}} s_{\mathrm{O}}^{1 \times 2} / k_{\mathrm{r}}, \quad \bar{d}=d / k_{\mathrm{r}}, \quad \bar{k}_{5}=k_{5} / k_{\mathrm{r}}
\end{aligned}
$$

into the following dimensionless form:

$$
\frac{\mathrm{d} \theta_{\mathrm{CO}}}{\mathrm{d} t}=F_{1}\left(\theta_{\mathrm{CO}}, \theta_{\mathrm{O}}\right)=\bar{D}_{1} \Delta \theta_{\mathrm{CO}}+\bar{p}_{\mathrm{CO}}\left(1-\theta_{\mathrm{CO}}^{3}\right)-\bar{d} \theta_{\mathrm{CO}}-\theta_{\mathrm{CO}} \theta_{\mathrm{O}},
$$


Table 1. Parameters of the model [6].

\begin{tabular}{c|c|c}
\hline \hline$T$ & $540 \mathrm{~K}$ & Temperature \\
\hline$p_{\mathrm{O}_{2}}$ & $9.75 \times 10^{-5}$ Torr & $\mathrm{O}_{2}$ partial pressure \\
\hline$k_{\mathrm{CO}}$ & $4.2 \times 10^{5} \mathrm{~s}^{-1} \mathrm{Torr}^{-1}$ & Impingement rate of CO \\
\hline$k_{\mathrm{O}}$ & $7.8 \times 10^{5} \mathrm{~s}^{-1} \mathrm{Torr}^{-1}$ & Impingement rate of $\mathrm{O}_{2}$ \\
\hline$d$ & $10.21 \mathrm{~s}^{-1}$ & CO desorption rate \\
\hline$D_{1}$ & $10^{-7} \mathrm{~cm}^{2} \mathrm{~s}^{-1}$ & CO diffusion rate \\
\hline$D_{2}$ & $10^{-10} \mathrm{~cm}^{2} \mathrm{~s}^{-1}$ & O diffusion rate \\
\hline$k_{\mathrm{r}}$ & $283.8 \mathrm{~s}^{-1}$ & Reaction rate \\
\hline$s_{\mathrm{CO}}$ & 1 & Oxygen sticking coefficient on the $1 \times 2$ phase \\
\hline$s_{\mathrm{O}, 1 \times 2}$ & 0.4 & Parameters for the structural phase transition \\
\hline$u_{0}, \delta u$ & $0.35,0.05$ & Phase transition rate \\
\hline$k_{5}$ & $1.61 \mathrm{~s}^{-1}$ &
\end{tabular}

$$
\begin{aligned}
& \frac{\mathrm{d} \theta_{\mathrm{O}}}{\mathrm{d} t}=F_{2}\left(\theta_{\mathrm{CO}}, \theta_{\mathrm{O}}, \theta_{1 \times 1}\right)=\bar{D}_{2} \Delta \theta_{\mathrm{O}}+\bar{p}_{\mathrm{O}_{2}}\left(1+\theta_{1 \times 1}\right)\left(1-\theta_{\mathrm{CO}}-\theta_{\mathrm{O}}\right)^{2}-\theta_{\mathrm{CO}} \theta_{\mathrm{O}}, \\
& \frac{\mathrm{d} \theta_{1 \times 1}}{\mathrm{~d} t}=F_{3}\left(\theta_{\mathrm{CO}}, \theta_{1 \times 1}\right)=\bar{D}_{3} \Delta \theta_{1 \times 1}+\bar{k}_{5}\left\{\left[1+\exp \left(\frac{u_{0}-\theta_{\mathrm{CO}}}{\delta u}\right)\right]^{-1}-\theta_{1 \times 1}\right\} .
\end{aligned}
$$

$s_{\mathrm{O}}=s_{\mathrm{O}}^{1 \times 1} \theta_{1 \times 1}+s_{\mathrm{O}}^{1 \times 2}\left(1-\theta_{1 \times 1}\right)=s_{\mathrm{O}}^{1 \times 2}\left(1+\theta_{1 \times 1}\right)$ under the assumption that for $\operatorname{Pt}(110)$ we have $s_{\mathrm{O}}^{1 \times 1} / s_{\mathrm{O}}^{1 \times 2} \simeq 2$.

The system of differential equations (2.4)-(2.6) with partial derivatives cannot be solved analytically. Therefore, the analysis of the system instabilities in time and space has been based on the methods of the linear stability theory and on numerical simulations. The system of equations $(2.4)-(2.6)$ in the linear approximation for the deviations from steady state $\delta \theta_{i}(\mathbf{r}, t)=\theta_{i}(\mathbf{r}, t)-\theta_{i, \mathrm{~s}}(\mathbf{r})$ looks as follows:

$$
\frac{\partial}{\partial t} \delta \theta_{i}(\mathbf{r}, t)=\sum_{j=1}^{3}\left(\frac{\partial F_{i}}{\partial \theta_{j}}\right)_{\theta_{k}=\theta_{k, \mathrm{~s}}} \delta \theta_{j}(\mathbf{r}, t)+\bar{D}_{i} \Delta \delta \theta_{i}(\mathbf{r}, t), \quad i, j=\mathrm{CO}, \mathrm{O}, 1 \times 1
$$

Stability of the system has been investigated using the method of normal modes concerning the perturbation periodic in space (normal mode) with a wavelength $\lambda$. To this end, we do the following substitution $\delta \theta_{i}(\mathbf{r}, t) \sim \mathrm{e}^{\omega t+\mathrm{ikr}}$, where $k=|\mathbf{k}|=2 \pi / \lambda$ is a wave number, and we obtain the following linear system of equations

$$
\sum_{j=1}^{3}\left[\left(\frac{\partial F_{i}}{\partial \theta_{j}}\right)_{\theta_{k}=\theta_{k, \mathrm{~s}}}-\bar{D}_{i} k^{2} \delta_{i j}-\omega \delta_{i j}\right] \delta \theta_{j}=0, \quad i=1,2,3
$$

Stability analysis requires a solution of the secular equation

$$
\operatorname{det}\left\|\left(\frac{\partial F_{i}}{\partial \theta_{j}}\right)_{\theta_{k}=\theta_{k, \mathrm{~s}}}-\bar{D}_{i} k^{2} \delta_{i j}-\omega \delta_{i j}\right\|=0
$$

whereof we get an equation for $\omega(k)$ :

$$
\omega^{3}-b(k) \omega^{2}+c(k) \omega-d(k)=0,
$$


where we have introduced the next notations:

$$
\begin{aligned}
& b(k)=\sigma-k^{2}\left(\bar{D}_{1}+\bar{D}_{2}+\bar{D}_{3}\right), \\
& c(k)=\Sigma-k^{2}\left[\bar{D}_{1}\left(a_{22}+a_{33}\right)+\bar{D}_{2}\left(a_{11}+a_{33}\right)+\bar{D}_{3}\left(a_{11}+a_{22}\right)\right]+k^{4}\left(\bar{D}_{1} \bar{D}_{2}+\bar{D}_{1} \bar{D}_{3}+\bar{D}_{2} \bar{D}_{3}\right), \\
& d(k)=\Delta-k^{2} \sum_{i=1}^{3} \bar{D}_{i} \eta_{i}+k^{4}\left(a_{11} \bar{D}_{2} \bar{D}_{3}+a_{22} \bar{D}_{1} \bar{D}_{3}+a_{33} \bar{D}_{1} \bar{D}_{2}\right)-k^{6} \bar{D}_{1} \bar{D}_{2} \bar{D}_{3} .
\end{aligned}
$$

Here, $a_{i j}=\left(\partial F_{i} / \partial \theta_{j}\right)_{\theta_{k}=\theta_{k, \mathrm{~s}}}, \sigma=a_{11}+a_{22}+a_{33}$ is the trace of the characteristic matrix $\left\{a_{i j}\right\}$, $\Delta=a_{11}\left(a_{22} a_{33}-a_{23} a_{32}\right)-a_{12}\left(a_{21} a_{33}-a_{23} a_{31}\right)+a_{13}\left(a_{21} a_{32}-a_{22} a_{31}\right)$ is its determinant, $\Sigma=\sum_{i=1}^{3} \eta_{i}$, where $\eta_{i}=a_{j j} a_{l l}-a_{j l} a_{l j}, i \neq j \neq l$. For our model,

$$
\begin{aligned}
& a_{11}=-3 \bar{p}_{\mathrm{CO}} \theta_{\mathrm{CO}, \mathrm{s}}^{2}-\bar{d}-\theta_{\mathrm{O}, \mathrm{s}}, \quad a_{12}=-\theta_{\mathrm{CO}, \mathrm{s}}, \quad a_{13}=0, \\
& a_{21}=-2 \bar{p}_{\mathrm{O}_{2}}\left(1+\theta_{1 \times 1, \mathrm{~s}}\right)\left(1-\theta_{\mathrm{CO}, \mathrm{s}}-\theta_{\mathrm{O}, \mathrm{s}}\right)-\theta_{\mathrm{O}, \mathrm{s}}, \\
& a_{22}=-2 \bar{p}_{\mathrm{O}_{2}}\left(1+\theta_{1 \times 1, \mathrm{~s}}\right)\left(1-\theta_{\mathrm{CO}, \mathrm{s}}-\theta_{\mathrm{O}, \mathrm{s}}\right)-\theta_{\mathrm{CO}, \mathrm{s}}, \\
& a_{23}=\bar{p}_{\mathrm{O}_{2}}\left(1-\theta_{\mathrm{CO}, \mathrm{s}}-\theta_{\mathrm{O}, \mathrm{s}}\right)^{2}, \\
& a_{31}=\frac{\bar{k}_{5}}{\delta u} \frac{\exp \left(\frac{u_{0}-\theta_{\mathrm{CO}, \mathrm{s}}}{\delta u}\right)}{\left[1+\exp \left(\frac{u_{0}-\theta_{\mathrm{CO}, \mathrm{s}}}{\delta u}\right)\right]^{2}}, \quad a_{32}=0, \quad a_{33}=-\bar{k}_{5} .
\end{aligned}
$$

Equation (2.9) is a cubic equation with real coefficients. In a general case, its solutions can contain both real and imaginary parts, i.e., $\omega(k)=\operatorname{Re} \omega(k)+\mathrm{i} \operatorname{Im} \omega(k)$. The component $\operatorname{Re} \omega(k)$ describes the stability of a solution $\left(\delta \theta_{\mathrm{CO}, k}(\omega), \delta \theta_{\mathrm{O}, k}(\omega), \delta \theta_{1 \times 1, k}(\omega)\right)$ and defines the process of relaxation, while $\operatorname{Im} \omega(k)$ sets the frequency of the oscillating process. The system is stable if

$$
\operatorname{Re} \omega(k)<0 \quad \text { for } \forall k \text {, }
$$

that is, when all normal modes are exponentially reduced. In the case when at least for one mode at a certain $k$ inequality $\operatorname{Re} \omega(k)>0$ becomes true, the whole system becomes unstable because the amplitude of the corresponding motion increases.

It is well-known that coefficients of a cubic equation and its roots are connected by the relations:

$$
\begin{aligned}
b & =\omega_{1}+\omega_{2}+\omega_{3}, \\
c & =\omega_{1} \omega_{2}+\omega_{1} \omega_{3}+\omega_{2} \omega_{3}, \\
d & =\omega_{1} \omega_{2} \omega_{3}, \\
b c-d & =\left(\omega_{1}+\omega_{2}\right)\left(\omega_{1}+\omega_{3}\right)\left(\omega_{2}+\omega_{3}\right) .
\end{aligned}
$$

Consequently, as follows from relations (2.11) and (2.12), a homogeneous state of the whole system is stable if

$$
b<0, \quad c>0, \quad d<0, \quad b c-d<0 .
$$

The violation of any of inequalities 2.13 means that a bifurcation has occurred in the system. The broken condition $d<0$ means the appearance of one real positive eigenvalue in the system. The broken condition $b c-d<0$ means that there are two complex conjugate eigenvalues with a positive real part. The first case corresponds to the Turing bifurcation, and the second corresponds to the Hopf one. is

Function $d\left(k^{2}\right)=\Delta-\alpha_{\mathrm{T}} k^{2}+\beta_{\mathrm{T}} k^{4}-\delta_{\mathrm{T}} k^{6}$ is a cubic parabola which has local extremes. The maximum

$$
d_{\max }\left(k_{\mathrm{T}}^{2}\right)=\Delta+\frac{1}{27 \delta_{\mathrm{T}}^{2}}\left[2\left(\beta_{\mathrm{T}}^{2}-3 \alpha_{\mathrm{T}} \delta_{\mathrm{T}}\right)^{\frac{3}{2}}+\beta_{\mathrm{T}}\left(2 \beta_{\mathrm{T}}^{2}-9 \alpha_{\mathrm{T}} \delta_{\mathrm{T}}\right)\right]
$$


and is reached at the point $k_{\mathrm{T}}^{2}=\left(\beta_{\mathrm{T}}+\sqrt{\beta_{\mathrm{T}}^{2}-3 \alpha_{\mathrm{T}} \delta_{\mathrm{T}}}\right) / 3 \delta_{\mathrm{T}}^{2}$. Here, $\alpha_{\mathrm{T}}=\sum_{i=1}^{3} \bar{D}_{i} \eta_{i}, \beta_{\mathrm{T}}=a_{11} \bar{D}_{2} \bar{D}_{3}+$ $a_{22} \bar{D}_{1} \bar{D}_{3}+a_{33} \bar{D}_{1} \bar{D}_{2}, \delta_{\mathrm{T}}=\bar{D}_{1} \bar{D}_{2} \bar{D}_{3}$. For the Turing bifurcation, it is necessary that in a certain range of wave numbers, $d\left(k^{2}\right)$ should become greater than zero,

$$
d_{\max }\left(k_{\mathrm{T}}^{2}\right)>0 .
$$

In [19], it is affirmed that this is possible only if at least one of the coefficients on the main diagonal of matrix $\left\{a_{i j}\right\}$ is greater than zero (a well-known condition for the existence of autocatalysis).

The condition for the Hopf bifurcation can be obtained in a similar way and is as follows:

$$
F_{\max }\left(k_{0}^{2}\right)=b c-d=\sigma \Sigma-\Delta+\frac{1}{27 \delta_{\mathrm{V}}^{2}}\left[2\left(\beta_{\mathrm{V}}^{2}-3 \alpha_{\mathrm{V}} \delta_{\mathrm{V}}\right)^{\frac{3}{2}}+\beta_{\mathrm{V}}\left(2 \beta_{\mathrm{V}}^{2}-9 \alpha_{\mathrm{V}} \delta_{\mathrm{V}}\right)\right]>0
$$

where $k_{0}^{2}=\left(\beta_{\mathrm{V}}+\sqrt{\beta_{\mathrm{V}}^{2}-3 \alpha_{\mathrm{V}} \delta_{\mathrm{V}}}\right) / 3 \delta_{\mathrm{V}}^{2}$. Here,

$$
\begin{aligned}
\alpha_{\mathrm{V}}= & \bar{D}_{1}\left(\sigma^{2}-a_{11}^{2}-a_{13} a_{31}-a_{12} a_{21}\right)+\bar{D}_{2}\left(\sigma^{2}-a_{22}^{2}-a_{23} a_{32}-a_{12} a_{21}\right) \\
& +\bar{D}_{3}\left(\sigma^{2}-a_{33}^{2}-a_{13} a_{31}-a_{23} a_{32}\right), \\
\beta_{\mathrm{V}}= & \left(\bar{D}_{1}+\bar{D}_{3}\right)\left(\bar{D}_{2}+\bar{D}_{3}\right)\left(a_{11}+a_{22}\right)+\left(\bar{D}_{1}+\bar{D}_{2}\right)\left(\bar{D}_{2}+\bar{D}_{3}\right)\left(a_{11}+a_{33}\right) \\
& +\left(\bar{D}_{1}+\bar{D}_{2}\right)\left(\bar{D}_{1}+\bar{D}_{3}\right)\left(a_{22}+a_{33}\right), \\
\delta_{\mathrm{V}}= & \left(\bar{D}_{1}+\bar{D}_{2}\right)\left(\bar{D}_{1}+\bar{D}_{3}\right)\left(\bar{D}_{2}+\bar{D}_{3}\right) .
\end{aligned}
$$

Again, to satisfy the inequality (2.16), the sum of two coefficients on the main diagonal of matrix $\left\{a_{i j}\right\}$ must be greater than zero [19].

As we see, our diagonal coefficients $a_{11}, a_{22}$ and $a_{33}$ are negative for all values of the system parameters. This means that the catalytic $\mathrm{CO}$ oxidation reaction is not autocatalytic because, as it was mentioned above, for autocatalytic reactions, at least one of the diagonal coefficients must be greater than zero. Nevertheless, we further show that conditions of the existence of the Turing (2.15) and the Hopf 2.16 bifurcations can be satisfied in our non-autocatalytic system at certain values of the system parameters. We associate the emergence of these instabilities with an interaction of nonlinear local transformations with a positive feedback (i.e., surface phase transitions) and transport processes (diffusion) which spatially couple the system.

\section{Results and discussion}

\subsection{Parametric analysis}

Using conditions of the existence of the Turing $(2.15)$ and the Hopf $(2.16)$ bifurcations, we choose the regions in $\left(\bar{p}_{\mathrm{CO}}, \bar{D}_{3}\right)$ parameter space which correspond to these instabilities (see figure 1 ). The region of their intersection corresponds to the presence of both instabilities. In the regions of low and high partial pressures $\bar{p}_{\mathrm{CO}}$, the system is stable. The region of intermediate partial pressures $\bar{p}_{\mathrm{CO}}$ where the oscillations occur coincides with the region of the structural surface transformation which is in agreement with the experimental observations by LEED [20]. The values of the parameters used in the calculations are presented in table 1 .

Figure 2 presents the dispersion dependences of real $\operatorname{Re} \omega$ and imaginary $\operatorname{Im} \omega$ parts for different regions of the stability diagram shown in figure 1 . We chose a point in each region to show how the dispersion curves change when moving from one region to another. Each of the subfigures in figure 2 corresponds to a point with the same name on the stability diagram. Figure 2 (a) demonstrates the behaviour of $\operatorname{Re} \omega$ and $\operatorname{Im} \omega$ in the region of low partial pressures $\bar{p}_{\mathrm{CO}}$ where the system is stable. As we see, $\operatorname{Re} \omega<0$ at any wave number $k$. In the region of high partial pressures $\bar{p}_{\mathrm{CO}}$, the dispersion dependences are similar.

In figure 2 (b), we have a realization of the Hopf bifurcation scenario with $\operatorname{Im} \omega\left(k_{0}\right)=0.402$, $\operatorname{Re} \omega\left(k_{0}\right)=0.002$, where $k_{0}=0$. It is well-known that the Hopf instability is the local dynamic 


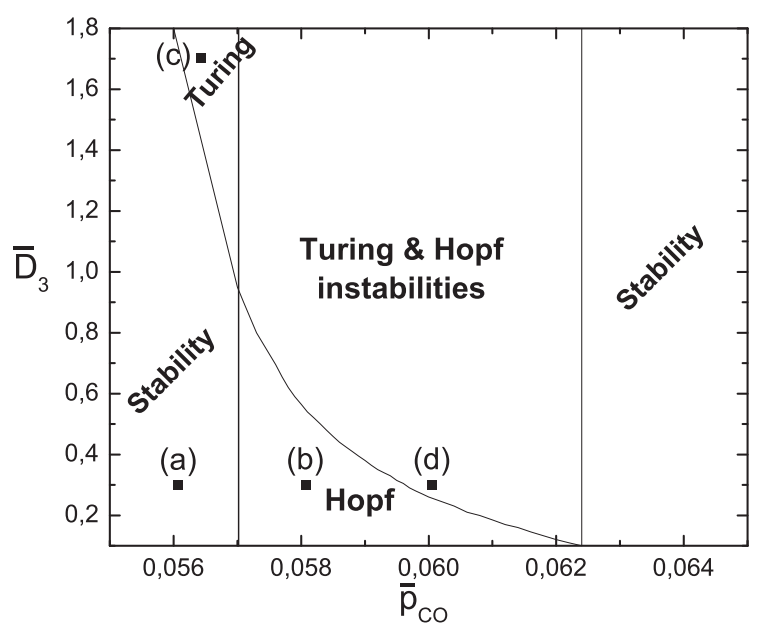

Figure 1. Stability diagram of the model in $\left(\bar{p}_{\mathrm{CO}}, \bar{D}_{3}\right)$ parameter space.
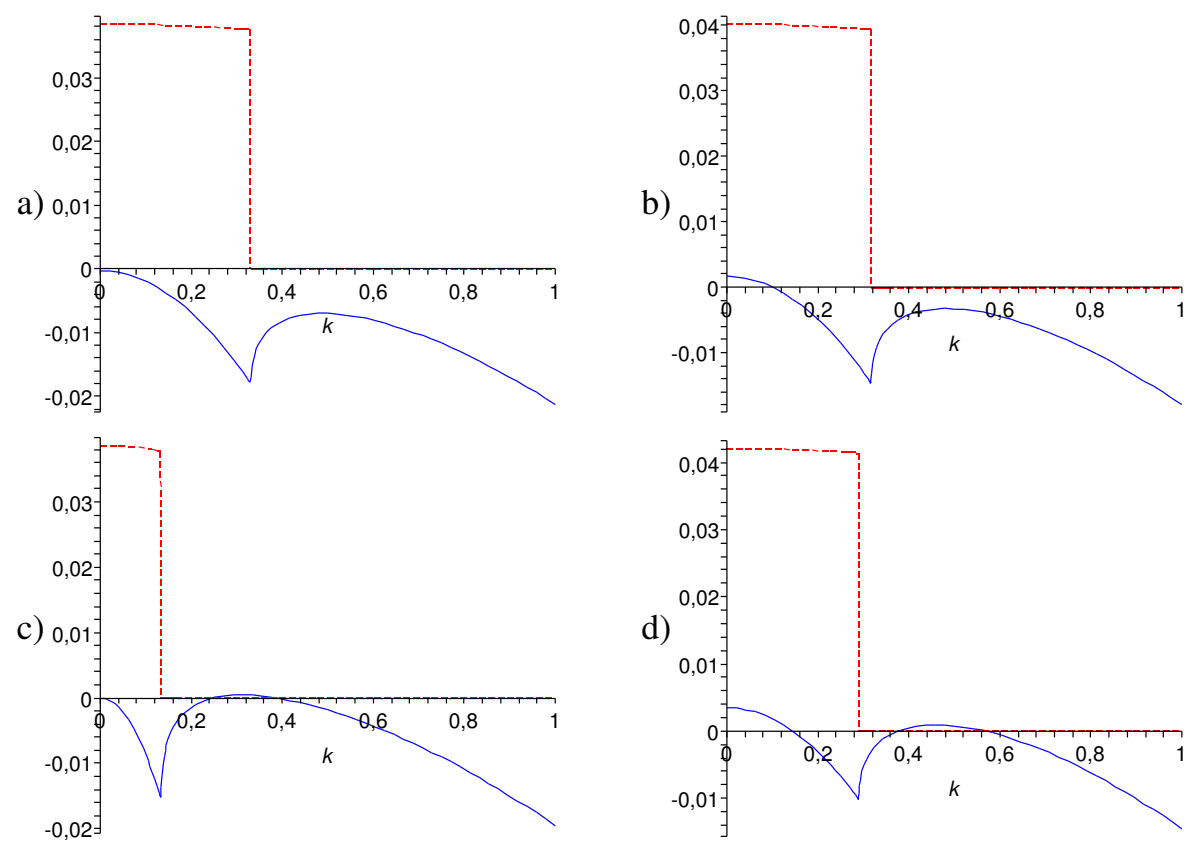

Figure 2. (Colour online) Dispersion dependences of real $\operatorname{Re} \omega$ (solid line) and imaginary $\operatorname{Im} \omega / 10$ (dashed line) parts on the wave number $k$ for the following sets of model parameters: (a) $\bar{p}_{\mathrm{CO}}=0.056, \bar{D}_{3}=0.3$ (stable region); (b) $\bar{p}_{\mathrm{CO}}=0.058, \bar{D}_{3}=0.3$ (Hopf instability); (c) $\bar{p}_{\mathrm{CO}}=0.0563, \bar{D}_{3}=1.7$ (Turing instability); and (d) $\bar{p}_{\mathrm{CO}}=0.06, \bar{D}_{3}=0.3$ (both instabilities), respectively. Other model parameters are the same in all cases.

instability arising in nonlinear systems with multiple time-scales, and requires the following conditions: $\operatorname{Im} \omega\left(k_{0}\right) \neq 0, \operatorname{Re} \omega\left(k_{0}\right)>0$, where $k_{0}=0$ [13]. In the phase space of the system, it causes a new attractor - a closed orbit called the limit cycle [1]. As a result of the Hopf bifurcation, an evolution of the system takes place by the states of the limit cycle. The instability of such type generates patterns periodic in time.

As figure 2 (c) depicts, depending on the model parameters, the Turing instability can occur in the system as well. In contrast to the Hopf bifurcation, the Turing bifurcation is not dynamic and is caused by the diffusion. It requires $\operatorname{Im} \omega\left(k_{\mathrm{T}}\right)=0, \operatorname{Re} \omega\left(k_{\mathrm{T}}\right)>0$ where $k_{\mathrm{T}}>0$ is the value of wave number $k$ corresponding to the second peak of the curve $\operatorname{Re} \omega(k)$ [13]. As is seen in figure 2] (c), at a certain choice of the diffusion parameters of the system, namely $\bar{D}_{1}=0.035, \bar{D}_{2}=0.000035$ and $\bar{D}_{3}=1.7$, 
a)

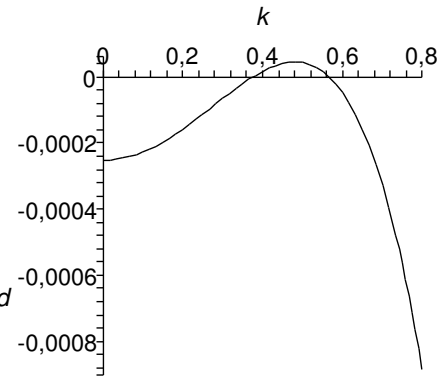

b)

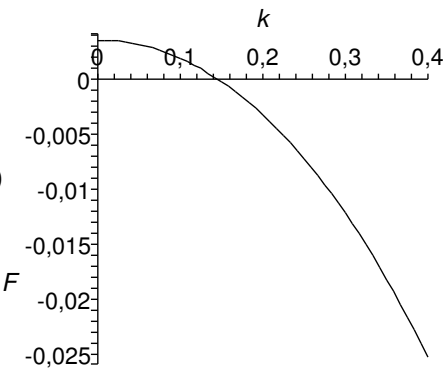

Figure 3. Dependences of the coefficients $d$ (subfigure a) and $F$ (subfigure b) on the wave number $k$ at a pressure $\bar{p}_{\mathrm{CO}}=0.06$.

the condition $\operatorname{Im} \omega\left(k_{\mathrm{T}}\right)=0, \operatorname{Re} \omega\left(k_{\mathrm{T}}\right)=0.001>0$ becomes true for $k_{\mathrm{T}}=0.31$. It causes concentration patterns periodic in space and stationary in time called the Turing patterns.

In figure 2 (d), dispersion curves are obtained in the system whose parameters satisfy both the conditions of the Turing instability and the Hopf one. Thus, the system can lose stability of the homogeneous state in two ways - either through the Hopf bifurcation leading to the temporal patterns formation (oscillations) in the system or through the Turing bifurcation that leads to the formation of regular spatial patterns. Moreover, bifurcations will take place in different ranges of wave numbers which do not overlap, with $k_{\mathrm{T}}>k_{0}$.

Additionally, using analytical conditions $2.15,2.16$, we have plotted $d\left(k^{2}\right)$ and $F\left(k^{2}\right)$ as functions of wave numbers $k$ for a set of the system parameters corresponding to figure 2(d). The result is shown in figure 3 (a) and (b), respectively. We can see that the maxima of the curves lie in the region of positive values and are as follows:

$$
d_{\max }\left(k_{\mathrm{T}}^{2}\right)=5 \cdot 10^{-5}>0, \quad F_{\max }\left(k_{0}^{2}\right)=0.0037>0 .
$$

$d_{\max }>0$ means the appearance of one real positive eigenvalue in the system: $\omega_{1}=0.001, \omega_{2}=-0.069$, $\omega_{3}=-0.724$. In the case of $F_{\max }>0$, we have two complex conjugate eigenvalues with a positive real part: $\omega_{1,2}=0.003 \pm 0.419 \mathrm{i}, \omega_{3}=-0.725$. The first case corresponds to the Turing bifurcation, and the second corresponds to the Hopf one. The numbers used above for the values of model parameters are the only special cases. The model is more general and, perhaps, it could be used not only in this particular system, which is considered as an example. Thus, we have shown that the Turing and the Hopf bifurcations can be observed in such systems despite their non-autocatalyticity.

\subsection{Effect of surface inhomogeneities}

To investigate the effect of inhomogeneities on the surface, we consider an one-dimensional Pt(110) substrate of a size $L_{x}=1 \mu \mathrm{m}$ with various surface phases — reconstructed central $1 \times 2$ phase surrounded by an unreconstructed $1 \times 1$ phase. Boundary conditions were chosen assuming that there is no flow through the boundary of the interval $[0,1]$. The initial conditions were set as follows:

$$
\begin{aligned}
\theta_{\mathrm{CO}}(x, t=0) & =\theta_{\mathrm{CO}, \mathrm{s}}, \\
\theta_{\mathrm{O}}(x, t=0) & =\left\{\begin{array}{cc}
\theta_{\mathrm{O}, \mathrm{s}}, & x<0.3 \text { and } x>0.7, \\
0, & 0.3<x<0.7,
\end{array}\right. \\
\theta_{1 \times 1}(x, t=0) & =\left\{\begin{array}{cc}
1, & x<0.3 \text { and } x>0.7, \\
0, & 0.3<x<0.7
\end{array}\right.
\end{aligned}
$$

Parameters of the reaction and diffusion correspond to the homogeneous oscillating state. This means that if the entire surface of the substrate had a uniform structure, the temporal behavior would be characterized by homogeneous periodic oscillations of coverages $\theta_{\mathrm{CO}}(x, t)=\theta_{\mathrm{CO}}(t), \theta_{\mathrm{O}}(x, t)=\theta_{\mathrm{O}}(t)$ and by the local fraction of the surface area in the unreconstructed $1 \times 1$ phase $\theta_{1 \times 1}(x, t)=\theta_{1 \times 1}(t)$. 
a)

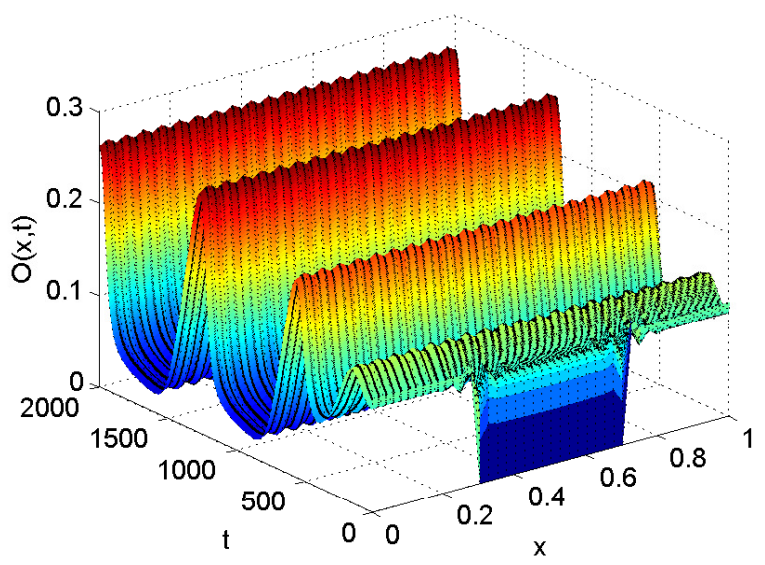

b)

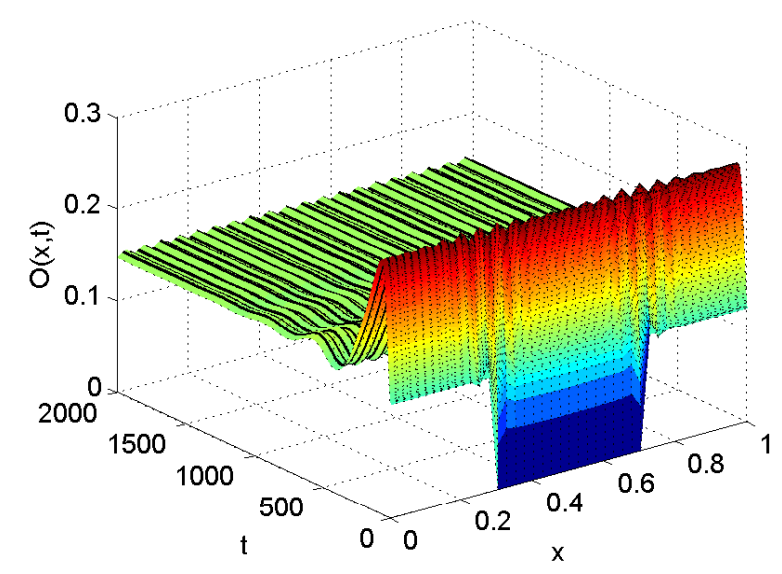

Figure 4. (Colour online) Spatiotemporal distributions of the oxygen coverage $\theta_{\mathrm{O}}$ at pressures $\bar{p}_{\mathrm{CO}}=$ 0.06 (a) and $\bar{p}_{\mathrm{CO}}=0.053(\mathrm{~b})$.

For the case of the reconstructed $1 \times 2$ phase being located inside the unreconstructed $1 \times 1$ phase, the gradients of the adsorbate coverages and of the surface geometry near the $1 \times 2 / 1 \times 1$-interfaces lead to the transition to a highly nonuniform state, which, in its turn, leads to a deformation of the wave front. To see this, in figure 4 we present the evolution of the oxygen coverage $\theta_{\mathrm{O}}$ at different values of pressure $\bar{p}_{\mathrm{CO}}$. Figure 4 (a) shows that at a partial pressure $\bar{p}_{\mathrm{CO}}=0.06$, an auto-oscillatory regime appears in the system if the condition 2.16) of the existence of the Hopf bifurcation is satisfied. Figure 4 (b) demonstrates that at pressure $\bar{p}_{\mathrm{CO}}=0.053$, the system evolves to a steady state through damped oscillations. As we can see, a perturbation of the initial spatial homogeneous distributions of oxygen coverage and surface geometry leads to a growth of perturbations by the Turing mechanism and to the formation of regular spatiotemporal [figure 4(a)] and spatial [figure 4(b)] patterns with durable coexistence of the regions with higher and lower oxygen concentrations on the surface.

Figure 5 presents a time evolution of the spatial distribution of oxygen coverage $\theta_{\mathrm{O}}$ at different moments of time. As is seen in the figure, the distribution of oxygen on the surface is of an oscillating character. At initial stages of time evolution, the amplitude of oscillations is maximal just at the interfaces. Homogeneous periodic oscillations of $\theta_{\mathrm{O}}$ coverage along the entire surface are observed over a long period of time.

Let us consider a case of a two-dimensional $\operatorname{Pt}(110)$ surface of size $L_{x}=L_{y}=1 \mu \mathrm{m}$ with different surface phases - a reconstructed $1 \times 2$ phase in the center and an unreconstructed $1 \times 1$ phase at the edges. Boundary and initial conditions were defined similarly to the previous one-dimensional case.

In the presence of the only Hopf instability [dispersion curves in figure2](b)], perturbation of the initial 
a)

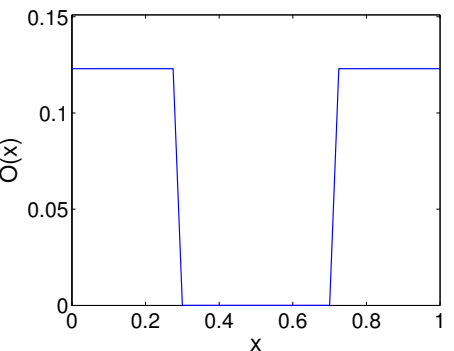

c)

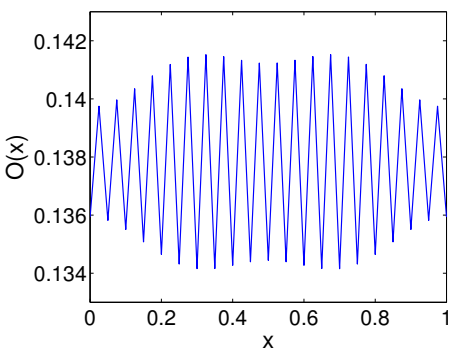

b) $\stackrel{x}{\circ}$

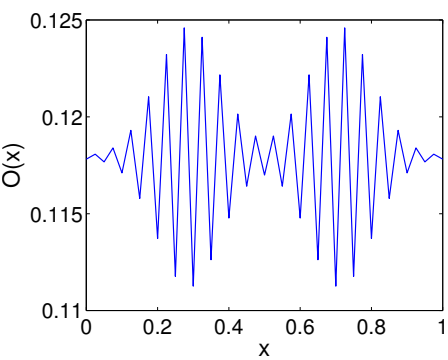

d) $\stackrel{x}{0}$

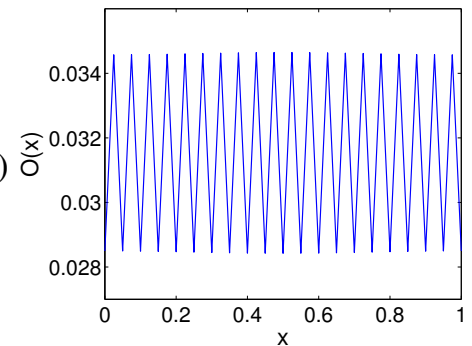

Figure 5. (Colour online) Time evolution of the spatial distribution of oxygen coverage $\theta_{\mathrm{O}}$ at pressure $\bar{p}_{\mathrm{CO}}=0.06$ at the moments $t=0$ (a), $t=50$ (b), $t=200(\mathrm{c})$, and $t=1000(\mathrm{~d})$, respectively.

spatial distribution of oxygen and surface geometry leads to the appearance of surface inhomogeneities at the initial stages of time evolution. Upon increasing the time, distributions of $\mathrm{CO}$ and oxygen become homogeneous in space but oscillating in time - we observe homogeneous periodic time oscillations of both coverages along the entire surface. Distribution of the surface phase $\theta_{1 \times 1}$ becomes homogeneous in space and stationary in time.

In the case of the coexistence of both instabilities [dispersion curves in figure2(d)], we observe the emergence of spatiotemporal patterns for the $\theta_{\mathrm{CO}}$ and $\theta_{\mathrm{O}}$ coverages. The distribution of the surface phase $\theta_{1 \times 1}$ becomes, as in the previous case, almost homogeneous in space and stationary in time. In figure 6 , several patterns are presented in the form of amplitude maps obtained at different moments of time using numerical simulations. We observe oscillating nonuniform distributions of adsorbate coverages with coexistence of the regions of high and low concentrations on the surface. These are traveling waves of chemical concentrations observed during experimental investigations of the catalytic $\mathrm{CO}$ oxidation under low pressure conditions on $\mathrm{Pt}(110)$, see, e.g. [21, 22]. Upon a subsequent increase of time $t>2750$, no fundamentally new spatial distributions of $\mathrm{CO}$ and oxygen were observed. In general, the appearing spatiotemporal patterns depend on a specific choice of the system parameters.

\section{Conclusions}

The catalytic carbon monoxide oxidation reaction model taking diffusion processes on the $\operatorname{Pt}(110)$ surface into account has been considered. The dispersion dependences $\operatorname{Re} \omega$ and $\operatorname{Im} \omega$ on the wave number $k$ have been built. Despite the CO oxidation reaction being non-autocatalytic, we have shown that the analytic conditions of the existence of the Turing and the Hopf bifurcations can be satisfied at certain values of the system parameters. Thus, the system may lose its stability in two ways - either through the Hopf bifurcation leading to the formation of temporal patterns in the system or through the Turing bifurcation leading to the formation of regular spatial patterns. The regions corresponding to the existence of a particular bifurcation were identified in the parametric space. At a simultaneous implementation of both scenarios, spatiotemporal patterns for $\mathrm{CO}$ and oxygen coverages have been observed in the system. The emergence of these instabilities are associated with an interaction of surface phase transitions and diffusion processes that spatially couple the system. The appearing spatiotemporal patterns depend on a specific choice of the system parameters. In general, the case of both instabilities being possible is rather complicated and deserves a special attention. 

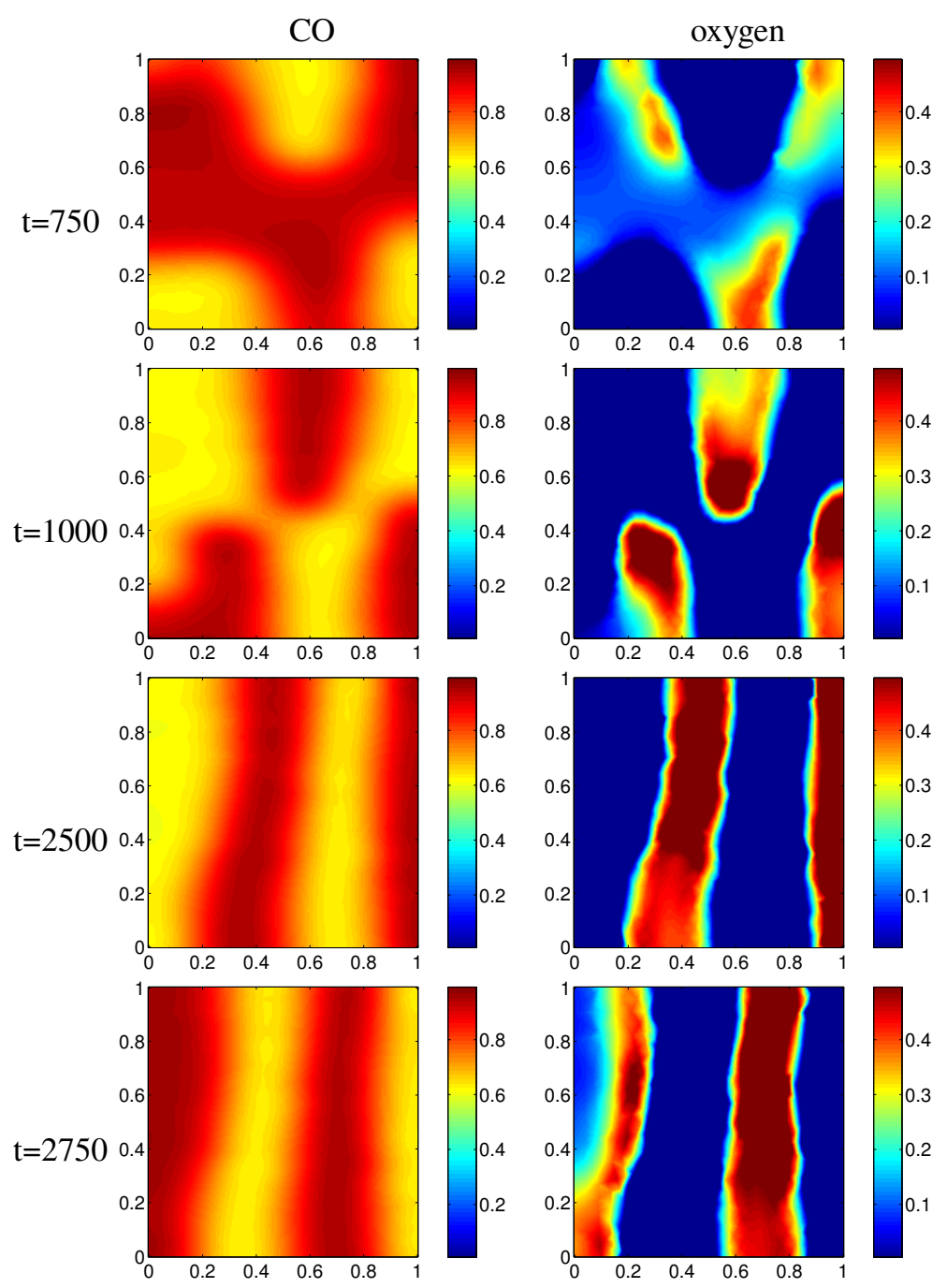

Figure 6. (Colour online) Examples of surface patterns for $\theta_{\mathrm{CO}}$ and $\theta_{\mathrm{O}}$ represented in the form of amplitude maps. The values of pressure $\bar{p}_{\mathrm{CO}}=0.06$ and of the coefficient $\bar{D}_{3}=0.3$ correspond to the region of coexistence of both instabilities. The size of the region is $1 \times 1 \mu \mathrm{m}$.

\section{References}

1. Ebeling W., Patterns Formation in Irreversible Processes, R\&C Dynamics, Moscow-Izhevsk, 2004, (in Russian).

2. Cross M., Greenside H., Pattern Formation and Dynamics in Nonequilibrium Systems, Cambridge University Press, New York, 2009.

3. Bertram M., Mikhailov A.S., Phys. Rev. E, 2001, 63, 066102, doi 10.1103/PhysRevE.63.066102

4. Kharchenko V.O., Kharchenko D.O., Kokhan S.V., Vernyhora I.V., Yanovsky V.V., Phys. Scr., 2012, 86, 055401, doi $10.1088 / 0031-8949 / 86 / 05 / 055401$

5. Verdasca J., Borckmans P., Dewel G., Phys. Rev. E, 2001, 64, No. 5, 055202, doi:10.1103/PhysRevE.64.055202

6. Bertram M., Mikhailov A.S., Phys. Rev. E, 2003, 67, No. 3, 036207, doi 10.1103/PhysRevE.67.036207

7. Hoyle R.B., Anghel A.T., Proctor M.R.E., King D.A., Phys. Rev. Lett., 2007, 98, No. 22, 226102, doi 10.1103/PhysRevLett.98.226102

8. Pavlenko N., Phys. Rev. E, 2008, 77, No. 2, 026203, doi 10.1103/PhysRevE.77.026203

9. Gorodetskii V.V., Drachsel W., Appl. Cat. A, 1999, 188, No. 1-2, 267, doi 10.1016/S0926-860X(99)00212-4

10. Von Oertzen A., Rotermund H.H., Mikhailov A.S., Ertl G., J. Phys. Chem. B, 2000, 104, 3155, doi $10.1021 /$ jp9927799 
11. Bertram M., Beta C., Pollmann M., Mikhailov A.S., Rotermund H.H., Ertl G., Phys. Rev. E, 2003, 67, 036208, doi $10.1103 /$ PhysRevE.67.036208

12. Gichan O.I., Lerman L.B., Grechko L.G., Sklyarov Yu.P., Bull. Kyiv Univ., Ser. Phys. Math., 2005, 1, 311 (in Ukrainian).

13. Gichan O.I., Grechko L.G., Bull. Kyiv Univ., Ser. Phys. Math., 2007, 4, 311 (in Ukrainian).

14. Vanag V.K., Phys. Usp., 2004, 174, No. 9, 991 (in Russian).

15. Krischer K., Eiswirth M., Ertl G., J. Chem. Phys., 1992, 96, 9161, doi:10.1063/1.462226.

16. Bär M., Gottschalk N., Eiswirth M., Ertl G., J. Chem. Phys., 1994, 100, 1202, doi $10.1063 / 1.466650$

17. Bzovska I.S., Mryglod I.M., Condens. Matter Phys., 2010, 13, No. 3, 34801, doi 10.5488/CMP.13.34801

18. Bzovska I.S., Mryglod I.M., Preprint of the Institute for Condensed Matter Physics, ICMP-15-02U, Lviv, 2015, (in Ukrainian).

19. Borina M.U., Polezhaev A.A., Comput. Res. Model., 2011, 3, No. 2, 135 (in Russian).

20. Eiswirth M., Möller P., Wetzl K., Imbihl R., Ertl G., J. Chem. Phys., 1989, 90, 510, doi 10.1063/1.456501.

21. Kim M., Bertram M., Pollmann M., von Oertzen A., Mikhailov A.S., Rotermund H.H., Ertl G., Science, 2001, 292, 1357, doi $10.1126 /$ science. 1059478

22. Beta C., Moula M.G., Mikhailov A.S., Rotermund H.H., Ertl G., Phys. Rev. Lett., 2004, 93, 188302, doi $10.1103 /$ PhysRevLett.93.188302

\section{Формування просторово-часових структур у трикомпонентній моделі реакції окислення монооксиду вуглецю}

\section{I.С. Бзовська, I.М. Мриглод}

Інститут фізики конденсованих систем НАН України, вул. Свєнціцького, 1, 79011 Львів, Україна

Досліджуються механізми формування просторово-часових структур у каталітичній реакції окислення СО з урахуванням процесів дифузії на неоднорідній поверхні Pt(110), яка містить структурно відмінні ділянки, що утворюються під час СО-індукованого переходу від реконструйованої $1 \times 2$ фази до об'ємної $1 \times 1$ фази. Незважаючи на те, що реакція окислення СО не $\epsilon$ автокаталітичною, ми показали, що аналітичні умови існування біфуркацій Тюринга та Хопфа виконуються в таких системах. Тобто, система може втрачати стійкість двома шляхами: або через біфуркацію Хопфа, що веде до утворення в системі часових структур, або через біфуркацію Тюринга, що призводить до формування регулярних просторових структур. При одночасній реалізації обох сценаріїв у системі отримано просторово-часові структури для величин покриття СО та кисню.

Ключові слова: реакційно-дифузійна модель, просторово-часові структури, біфуркація Хопфа, біфуркація Тюринга 


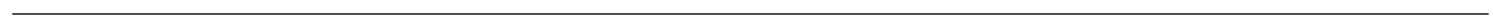

